\title{
PEMANFAATAN ANDROID PADA SISTEM PRESENSI KARYAWAN DI PT. GESCHOOL CERDAS MANDIRI
}

\author{
E.N. Tamatita, Angraini Kusumaningrum, Ade Ari Ardianto \\ Program Studi Teknik Informatika \\ Sekolah Tinggi Teknologi Adisutjipto Yogyakarta \\ informatika@stta.ac.id
}

\begin{abstract}
Presence is the most important activity, because it is related to productivity of employees and one part of human resources controll indicator which aim to improve the potential of human resources itself The function of presence programme is for knowing presence of employees by used android smartphone. The employees can entry their presence data by use the presence programme, they just need to touch the attendance button, check out from office button and also take a leave button, the result of entry data will be entered into database system in the form of an admin web. The function of the web is to determine the employees' data entry and add employees' data. The employees should used android smartphone with same wifi local area of the company that used also by the admin web because it became the benefits of local wifi. In this case we need three days for trial, with a wide range of trials from 10 users testing, 10 smartphones testing, access point testing, blackbox testing and also white box testing. The aim of user testing is done by employees with android smartphone is to know does the time result of entry data equal with the time result of admin in web. Smartphone trial by the employees is done by view notification alerts presence was accepted by the admin, the result show if the average is less than 20 seconds. Access point trial done by the admin, is to show the speed of access point received by androind smartphone is less than 10 seconds. Black box trial and white box trial done by admin, the flow of the web, and also the flow of android smartphone program get the 100\%. The result of three days trial finds that everything in presence program is going well.
\end{abstract}

Key word : White box, Black box, Presence, Android

\section{Pendahuluan}

Smartphone yang digunakan di Indonesia berguna sebagai komunikasi suara, video pengiriman data, data menggunakan provider yang menawarkan koneksi internet dengan sistem paket data internet. Sebagian besar pemilik dari ponsel pintar atau smartphone ini hanya digunakan untuk mengakses situs jejaring sosial yang salah satunya seperti facebook, twitter, path, dan instagram serta untuk permainan game yang tesedia pada playstore dengan secara gratis. Pemanfaatan handphone atau ponsel pintar yang guna mendukung dan mempermudah setiap pekerjaan. Dengan salah satunya pemanfaatan sistem presensi karyawan pada sebuah kantor ataupun perusahaan, Dengan menggunakan ponsel pintar atau sering disebut smartphone yang pada dasarnya dimiliki oleh setiap karyawan. Presensi merupakan kehadiran karyawan yang berkenaan dengan tugas dan kewajibannya. Pada umumnya perusahaan ataupun kantor selalu memperhatikan pegawainya untuk datang dan pulang tepat waktu, sehingga pekerjaan tidak tertunda. Ketika kehadiran seorang karyawan akan berpengaruh terhadap pekerjaan, sehingga perusahaan ataupun kantor dapat mencapai tujuan secara optimal.

Berdasarkan latar belakang, dapat disimpulkan permasalahan dalam melakukan tugas akhir ini, yaitu, bagaimana merancang aplikasi Android pada handphone atau smartphone yang dapat 
digunakan dalam melakukan sistem presensi kepegawaian dan bagaimana cara menghubungkan aplikasi berbasis Android ini pada sebuah server database. Batasan masalah dalam pembuatan sebuah aplikasi android aplikasi berjalan pada Android minimal 4.2, perangkat Android sebagai alat presensi. pada perangkat Android wifi harus kondisi aktif.

\section{Metode Penelitian}

2.1 Activity Diagram Berjalan

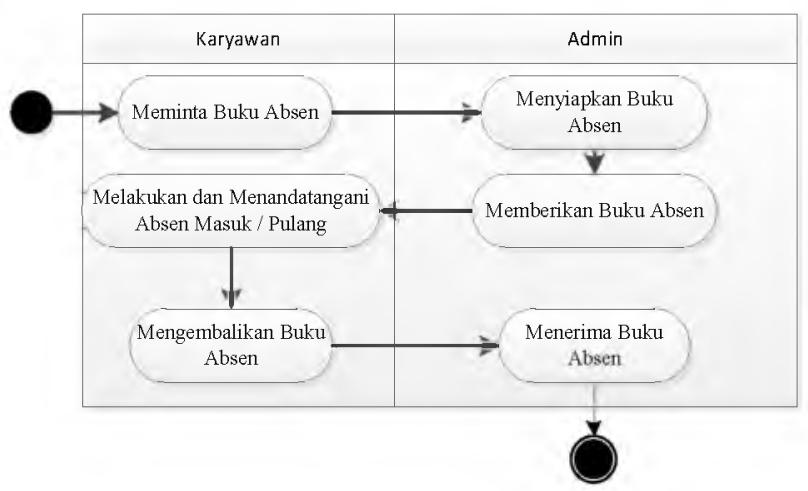

Gambar 1. Activity Diagram Absen

Gambar 1. Menunjukan activity diagram absen datang karyawan dengan sistem manual yang belum menggunakan sistem komputerisasi.

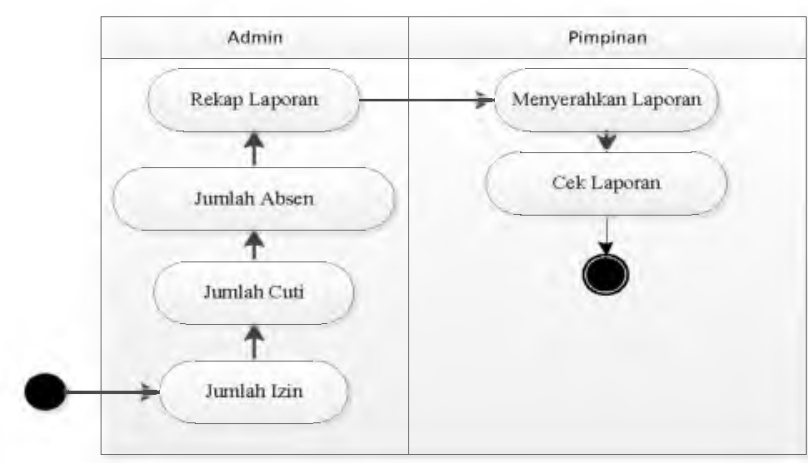

Gambar 2. Activity Diagram Laporan

Gambar 2. Menunjukan activity diagram laporan dengan menggunakan sistem manual untuk admin yang akan diberikan kepada pimpinan perusahaan. 


\subsection{Usecase Diagram}

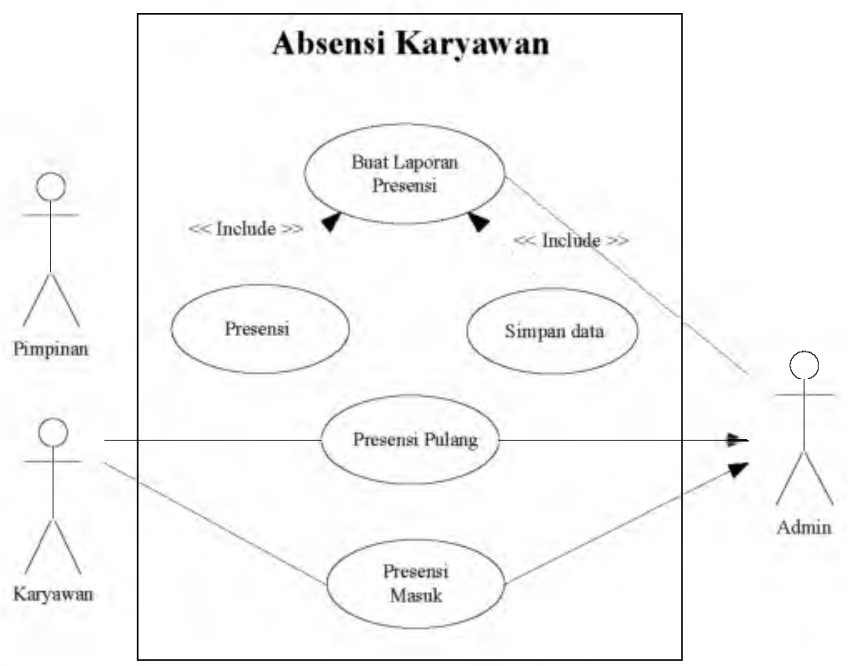

Gambar 3. Use case Diagram Presensi Manual

Gambar 3. Menunjukkan sistem presensi dengan menggunakan sistem manual dari pihak perusahan. Karyawan melakukan presensi masuk dan pulang diterima oleh admin dan admin menyimpan serta membuat laporan dikirim untuk pimpinan.

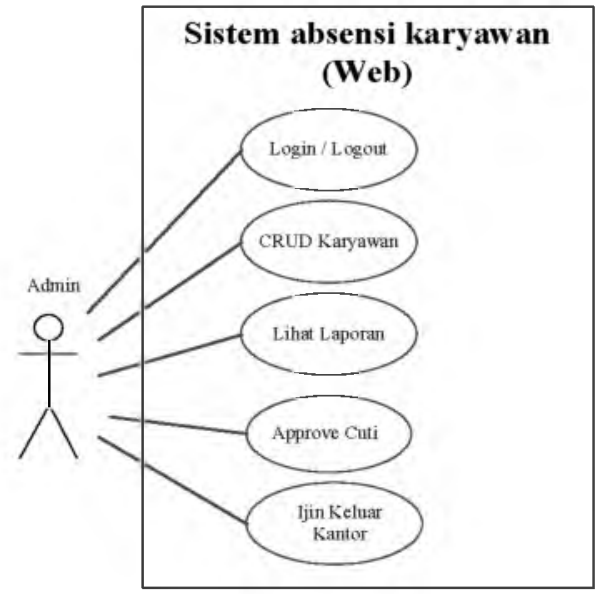

Gambar 4. Use case Diagram Admin Yang Diusulkan

Gambar 4 adalah usecase diagram admin yang diusulkan untuk membuat sistem presensi dengan mengunakan sistem komputerisai. Admin dapar melakukan login dan logout, CRUD (Create, Read, Update, Delete) karyawan, lihat laporan, approve cuti karyawan serta ijin karyawan. 


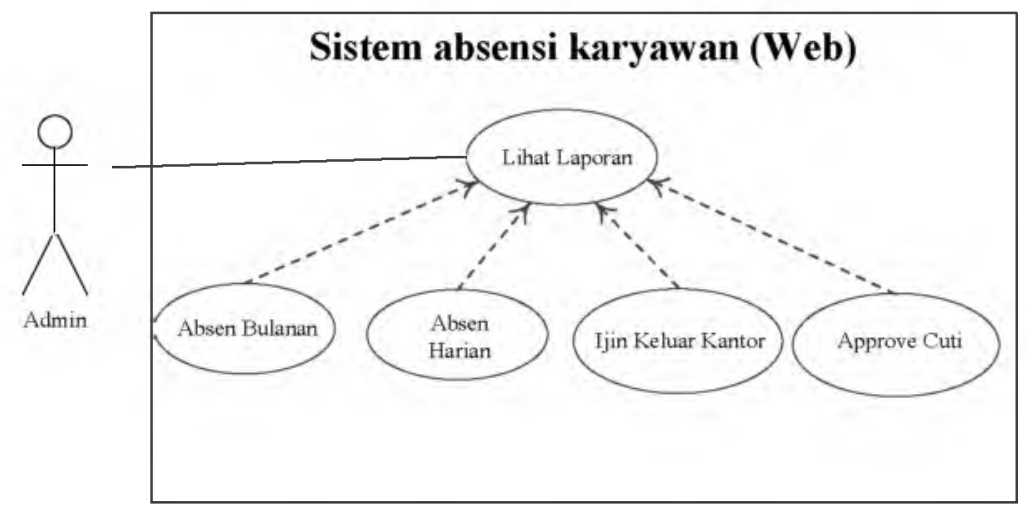

Gambar 5. Use case Diagram Admin Lihat Laporan

Gambar 5 menunjukan admin lihat laporan presensi dari presensi bulan, presensi harian, ijin keluar kantor serta approve cuti untuk karyawan.

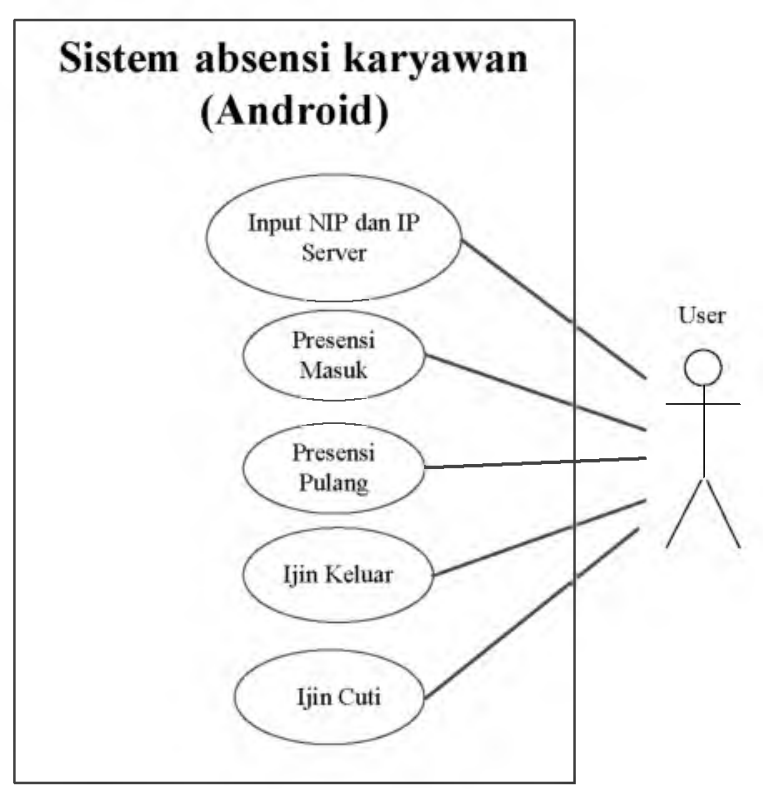

Gambar 6. Use case Diagram Karyawan Yang Diusulkan

Gambar 6 usecase diagram untuk karyawan dengan sistem android. Karyawan dapat menginputkan nip dan ip server guna registrasi awal, karyawan dapat melakukan presensi masuk, presensi pulang, ijin keluar kantor dan ijin cuti. 


\subsection{Class Diagram}

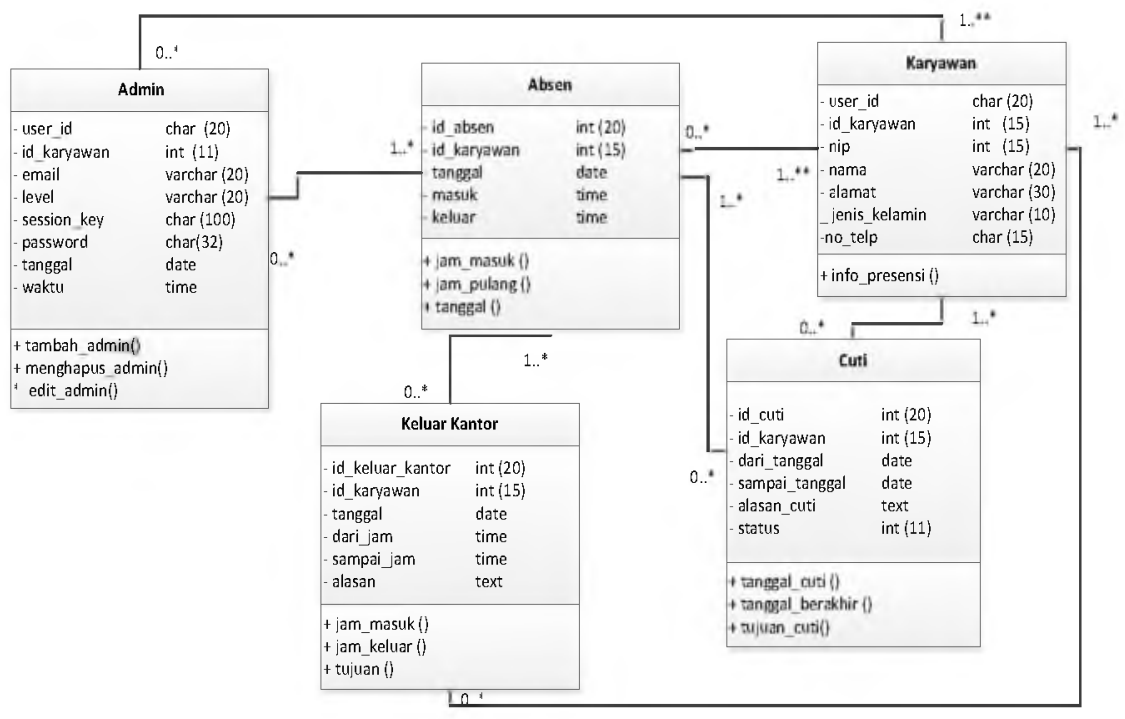

Gambar 7. Class Diagram Yang Diusulkan

Pada class diagram yang terdapat pada Gambar 7 yang menunjukan dari alur karyawan hingga, karyawan dapat melakukan presensi dan diterima oleh admin.

\subsection{Hasil dan Pengujian}

\subsection{Pengujian Access Point}

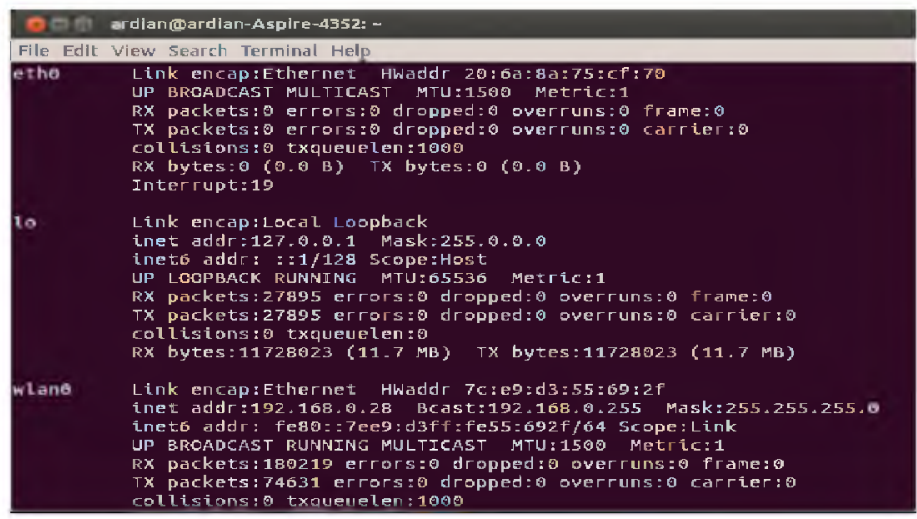

Gambar 8. Tampilan Pengujian Access Point

Gambar 8. Hasil dari terhubungnya access point terhadap server adalah pada gambar yang bertuliskan wlan0 dan terdapat informasi dari ip address. 


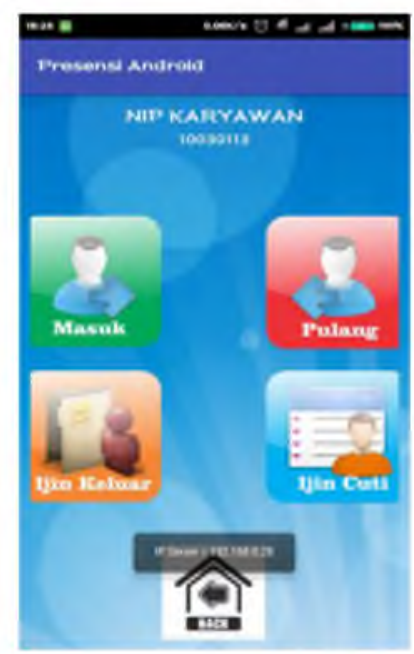

Gambar 9. Tampilan Hasil Android Terhubung Server

Pada pengujian access point, dari sisi android akan menerima pemberitahuan ip server 192.168.0.28 ip yang sama dengan server. Pada tampilan hasil android terdapat button untuk melakukan presensi masuk, presensi pulang, ijin keluar kantor, kembali keluar kantor dan ijin cuti.

\subsection{Pengujian Smartphone}

Tabel 1. Hasil Pengujian Smartphone

\begin{tabular}{|c|c|c|c|c|c|c|c|c|}
\hline \multirow[t]{2}{*}{ No } & \multirow{2}{*}{$\begin{array}{l}\text { Nama } \\
\text { Smartphone }\end{array}$} & \multirow{2}{*}{$\begin{array}{l}\text { Sistem } \\
\text { Operasi }\end{array}$} & \multicolumn{4}{|c|}{ Fitur Menu } & \multirow[t]{2}{*}{ Kecepatan } & \multirow[t]{2}{*}{ Ket } \\
\hline & & & Masuk & Pulang & Keluar & Cuti & & \\
\hline 1. & Asus Pedfone s & $\begin{array}{l}4.4 .4 \\
\text { (Kitkat) }\end{array}$ & $\checkmark$ & $\checkmark$ & $\checkmark$ & $\checkmark$ & 10 detik & $\begin{array}{l}\text { Berjalan } \\
\text { dengan } \\
\text { baik }\end{array}$ \\
\hline 2. & Zenfone 4 & $\begin{array}{l}4.4 .4 \\
\text { (Kitkat) }\end{array}$ & $\checkmark$ & $\checkmark$ & $\checkmark$ & $\checkmark$ & 10 detik & $\begin{array}{l}\text { Berjalan } \\
\text { dengan } \\
\text { baik }\end{array}$ \\
\hline 3. & Acer E380 & $\begin{array}{l}4.2 .3 \\
\text { (JellyBea } \\
\text { ns) }\end{array}$ & $\checkmark$ & $\checkmark$ & $\checkmark$ & $\checkmark$ & 9 detik & $\begin{array}{l}\text { Berjalan } \\
\text { dengan } \\
\text { baik }\end{array}$ \\
\hline 4. & Redmi 2 & $\begin{array}{l}4.4 .4 \\
\text { (Kitkat) }\end{array}$ & $\checkmark$ & $\checkmark$ & $\checkmark$ & $\checkmark$ & 8 detik & $\begin{array}{l}\text { Berjalan } \\
\text { dengan } \\
\text { baik }\end{array}$ \\
\hline 5. & Lenovo A526 & $\begin{array}{l}4.2 \\
\text { (JellyBea } \\
\text { ns) }\end{array}$ & $\checkmark$ & $\checkmark$ & $\checkmark$ & $\checkmark$ & 8 detik & $\begin{array}{l}\text { Berjalan } \\
\text { dengan } \\
\text { baik }\end{array}$ \\
\hline 6. & Lenovo A6000 & $\begin{array}{l}4.4 .4 \\
\text { (Kitkat) }\end{array}$ & $\checkmark$ & $\checkmark$ & $\checkmark$ & $\checkmark$ & 8 detik & $\begin{array}{l}\text { Berjalan } \\
\text { dengan } \\
\text { baik }\end{array}$ \\
\hline 7. & Lenovo A859 & $\begin{array}{l}4.2 .3 \\
\text { (JellyBea } \\
\text { ns) }\end{array}$ & $\checkmark$ & $\checkmark$ & $\checkmark$ & $\checkmark$ & 7 detik & $\begin{array}{l}\text { Berjalan } \\
\text { dengan } \\
\text { baik }\end{array}$ \\
\hline 8. & Redmi Note 1 & 4.4 .4 & $\checkmark$ & $\checkmark$ & $\checkmark$ & $\checkmark$ & 7 detik & Berjalan \\
\hline
\end{tabular}




\begin{tabular}{|l|l|l|l|l|l|l|l|l|}
\hline & & (Kitkat) & & & & & & $\begin{array}{l}\text { dengan } \\
\text { baik }\end{array}$ \\
\hline 9. & $\begin{array}{l}\text { Samsung } \\
\text { Galaxy Prime }\end{array}$ & $\begin{array}{l}4.4 .4 \\
\text { (Kitkat) }\end{array}$ & $\checkmark$ & $\checkmark$ & $\checkmark$ & $\checkmark$ & 5 detik & $\begin{array}{l}\text { Berjalan } \\
\text { dengan } \\
\text { baik }\end{array}$ \\
\hline 10. & Asus Zenfone 5 & $\begin{array}{l}4.2 .3 \\
\text { (JellyBea } \\
\text { ns) }\end{array}$ & $\checkmark$ & $\checkmark$ & $\checkmark$ & $\checkmark$ & 4 detik & $\begin{array}{l}\text { Berjalan } \\
\text { dengan } \\
\text { baik }\end{array}$ \\
\hline
\end{tabular}

Pada hasil pengujian smartphone dilakukan proses pengujian kecepatan penerimaan notifikasi dari sistem yang memberitahukan bahwa proses yang dilakukan di terima. Dalam pengujian ini di beri batasan pada smartphone dengan secara mamual smartphone yang melakukan proses dibawah dari 20 detik terhitung proses berjalan dengan baik. Rumus Presentase Penilaian $=$ Jumlah dari masing-masing penilaian / Total nilai akhir $* 100 \%$, dan mendapatkan hasil akhir 100\%

\subsection{Whitebox Testing}

Pengujian white-box digunakan untuk meyakinkan semua perintah dan kondisi pada aplikasi dieksekusi secara minimal. Pengujian white-box mengunakan dua tools yaitu flow graph yang digunakan untuk menggambarkan alur dari proses admin yang berbasis menggunakan web.

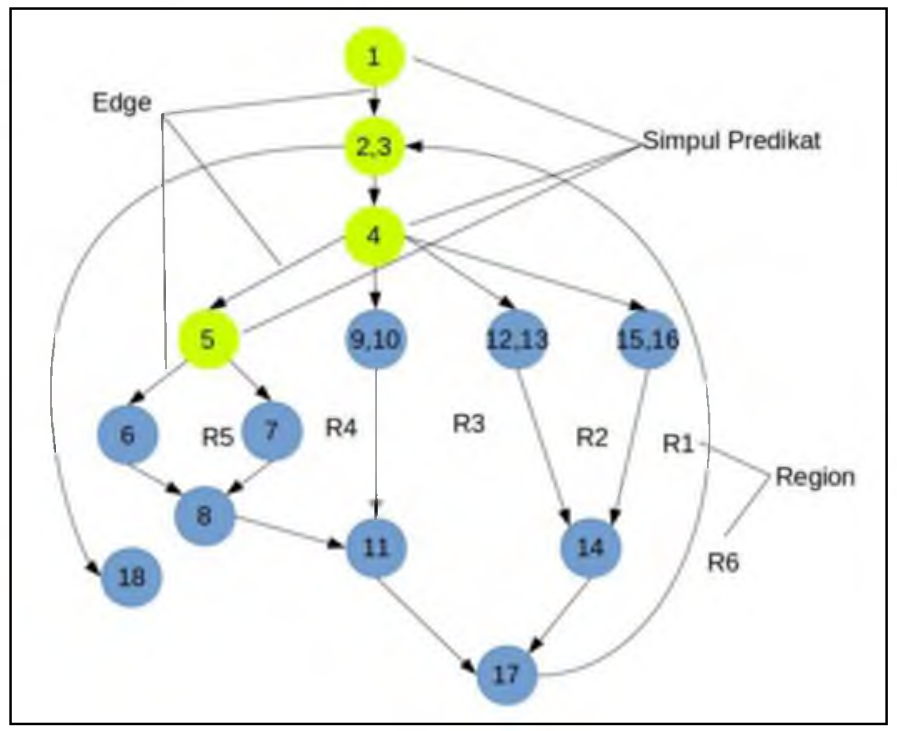

Gambar 10. Flowgraph Proses Sistem

$$
\begin{aligned}
& V(G)=E-N+2 \\
& V(G)=18-14+2 \\
& V(G)=4+2 \\
& V(G)=6
\end{aligned}
$$


Dimana :

$\mathrm{E}=$ jumlah edge pada grafik alir

$\mathrm{N}=$ jumlah node pada grafik alir

Tabel 2. Cyclomatic Complexity Pada Flowgraph

\begin{tabular}{|l|l|}
\hline Path 1 & $1-2-18$ \\
\hline Path 2 & $1-2-3-4-15-16-14-17-2-18$ \\
\hline Path 3 & $1-2-3-4-12-13-14-17-2-18$ \\
\hline Path 4 & $1-2-3-4-9-10-11-17-2-18$ \\
\hline Path 5 & $1-2-3-4-5-6-8-11-17-2-18$ \\
\hline Path 6 & $1-2-3-4-5-7-8-11-17-2-18$ \\
\hline
\end{tabular}

Tabel 2 menunjukan hasil penghitungan dari flowgraph dan menghasilkan 6 path dengan menggunakan tabel Cyclomatic Complexity. Cyclomatic Complexity merupakan suatu sistem pengukuran kuantitatif dari kompleksitas logika program.

Tabel 3. Tabel Hasil Pengujian White-box

\begin{tabular}{|c|c|c|c|c|c|c|}
\hline Hasil pengujian white-box & Ya & Tidak & Ya & Tidak & Ya & Tidak \\
\hline Path 1 & {$[\sqrt{ }]$} & & {$[\sqrt{ }]$} & & {$[\sqrt{ }]$} & \\
\hline Path 2 & {$[\sqrt{ }]$} & & {$[\sqrt{ }]$} & & {$[\sqrt{ }]$} & \\
\hline Path 3 & {$[\sqrt{ }]$} & & {$[\sqrt{ }]$} & & {$[\sqrt{ }]$} & \\
\hline Path 4 & {$[\sqrt{ }]$} & & {$[\sqrt{ }]$} & & {$[\sqrt{ }]$} & \\
\hline Path 5 & {$[\sqrt{ }]$} & & {$[\sqrt{ }]$} & & {$[\sqrt{ }]$} & \\
\hline Path 6 & {$[\sqrt{ }]$} & & {$[\sqrt{ }]$} & & {$[\sqrt{ }]$} & \\
\hline Hasil & 6 & & & & & \\
\hline Total & & & & & & \\
\hline
\end{tabular}

Presentase Penilaian $=$ Jumlah dari masing-masing penilaian $/$ Total nilai akhir $* 100 \%$. Dalam perhitungan white-box dilakukan pengujian selama 3 hari yang dimulai dari tanggal 28 Oktober 2015.

\section{Kesimpulan}

1. Aplikasi presensi android menyimpan semua data karyawan dengan menggunakan database mysql yang dihubungkan dengan menggunakan metode web service. Android yang harus terhubung wifi local serta web pada admin juga terhubung dengan wifi local

2. Berdasarkan hasil uji dari access point dengan hasil uji kecepatan 1 detik, white-box pengujian menggunakan 6 path dari alur flowgraph mendapatkan presentase $100 \%$, Smartphone pengujian dengan uji coba fitur dari aplikasi selama 3 hari mendapatkan hasil presentase $100 \%$. 


\section{Daftar Pustaka}

[1] Abeysinghe, S. 2008. RESTful PHP Web Services. Birmingham: Packet Publishing Ltd.

[2] Dennis, Alan, 2005. System Analysis and Design with UML Version 2.0, WILLEY, New Jersey

[3] Williams, Laurie. 2006. White-Box Testing, published in 2006 
E.N. Tamatita, Angraini Kusurmaningrum, Ade Ari Ardianto 